\title{
Antibiotic Susceptibility Pattern and Identification of Multidrug Resistant Novel Salmonella Strain in Poultry Chickens of Hathazari Region in Chattogram, Bangladesh
}

\author{
Kamrun Nahar Islam ${ }^{*}{ }^{(\mathbb{D})}$, Eshiika Eshaa1 (), Mahamudul Hassan', Tasneem Chowdhury ${ }^{1}$, \\ Sifat Uz Zaman ${ }^{2}$ \\ ${ }^{1}$ Department of Microbiology, University of Chittagong, Chattogram, Bangladesh \\ ${ }^{2}$ Infection Prevention and Control Division, Medlife Healthcare Limited, Dhaka, Bangladesh \\ Email: ${ }^{\star}$ knislam47@gmail.com
}

How to cite this paper: Islam, K.N., Eshaa, E., Hassan, M., Chowdhury, T. and Zaman, S.U. (2022) Antibiotic Susceptibility Pattern and Identification of Multidrug Resistant Novel Salmonella Strain in Poultry Chickens of Hathazari Region in Chattogram, Bangladesh. Advances in Microbiology, 12, 53-66.

https://doi.org/10.4236/aim.2022.122005

Received: December 25, 2021

Accepted: February 8, 2022

Published: February 11, 2022

Copyright ( 2022 by author(s) and Scientific Research Publishing Inc. This work is licensed under the Creative Commons Attribution International License (CC BY 4.0).

http://creativecommons.org/licenses/by/4.0/ (c) (i) Open Access

\begin{abstract}
Poultry chickens are potential source of transmission of zoonotic Salmonella, into human food chain, causing food-borne illness and also hindering development of poultry industry in Bangladesh. The non-judicious uses of antibiotics in poultry farm have increased the multidrug resistant bacteria. So, this study reports the occurrence of Salmonella in poultry samples (meat, egg, liver and cloacal swab) and the antimicrobial resistance pattern of the isolates. This study was carried out throughout the period of May 2019-March 2020, at the bacteriological laboratory in the Department of Microbiology, University of Chittagong. Isolates were identified on the basis of cultural and biochemical tests from a total of 25 broiler samples (meat, liver, eggshell and cloacal swab). Antibiotic susceptibility pattern was observed using Kirby-Bauer disk diffusion method. The overall detection rate of Salmonella was $48 \%(12 / 25)$ and the highest occurrence was noticed in raw meat $62.5 \%$ and the lowest in liver (37.5\%). The antimicrobial resistance tests revealed that all the isolates $(n=12)$ exhibited $100 \%$ resistance to vancomycin and cephalexin, followed by ampicillin (75\%), nalidixic acid (58.33\%), chloramphenicol (41.66\%), doxycycline $(50 \%)$, and neomycin (50\%). On the other hand, ciprofloxacin showed $83.33 \%$, ceftazidime and amoxicillin showed $91.6 \%$ sensitivity respectively. A considerably high proportion of isolates (11/12, 91.67\%) was resistant to three or more antibiotics and 6 multidrug profiles were observed. The ampicillin-chloramphenicol-nalidixic acid-neomycin-cephalexindoxycycline-vancomycin (4/12) was more frequently observed phenotype in multidrug profiles. Finally, two multidrug-resistant strains of Salmonella
\end{abstract}


were identified and classified based on their 16S ribosomal RNA gene sequences as Salmonella enterica subsp. enterica strain Eshaa2 and Salmonella enterica subsp. enterica strain Eshiika3 at NCBI GenBank with Accession no. MT163513 and MT164531 respectively. So, more attention should be focused on increasing antibiotic surveillance to cope with the spread of emerging resistance and on the alternative approaches.

\section{Keywords}

Antimicrobial Resistance, Chicken Meat, Multidrug-Resistant, Salmonella, Salmonellosis

\section{Introduction}

Despite global improvements in public health facilities, bacterial infections remain an important public health problem worldwide [1]. Among the pathogens, Salmonella is considered the most prevalent foodborne pathogen and has long been recognized as an important zoonotic bacterium of economic significance in animals and humans [2]. Salmonella agents that cause infection in humans are more common in poultry than in other animal species [3]. Therefore, poultry products could be one of the potential sources to harbor a diverse microbial community such as Salmonella enterica, the causative agent of salmonellosis [4]. Though there are several contributing factors such as consumption of raw or unsafe food, cross-contamination, poor personal hygiene, etc. for an outbreak of Salmonellosis in humans, the consumption of chicken products (e.g. meat, liver, and eggs) is considered as the primary route of transmission of Salmonella into the human food chain [5]. In poultry-originated food-borne outcomes, Salmonella ranks the highest in all cases linked to food consumption [6]. Salmonella was accounted for 1335 food-borne outbreaks and 36,940 associated illnesses that were reported to Food Disease Outbreak Surveillance System from 1999 to 2008 and poultry products were responsible for a higher percentage of Salmonella outbreaks of infection compared to other food commodities [7].

From the FAO statement, the production of poultry meat and eggs in Bangladesh is growing rapidly over the last 15 years. Poultry meat production has increased from 660 tons in 1990 to 6.2 million metric tons in 2016 and egg production has increased 11,912.4 million over the same period [8]. The growth rate of chicken production in Bangladesh was 5.3\% per year and consumption of broiler meat and eggs could grow by $95 \%$ and $78 \%$ respectively, in 2020 [9]. This growth will be being driven by the increase in market demand [10]. Salmonellosis is important as both a cause of clinical disease in commercial poultry that hindered the development of the poultry industry in Bangladesh and as a source of human food-borne zoonotic diseases [11]. Ignorance of the veterinary medical profession and its extension services, poor people without any knowledge of zoonotic diseases who are in close contact with livestock and their products and 
unhygienic processing, maintaining, and marketing the livestock and livestock products have made the situation graver in Bangladesh [12]. In poultry farming, the use of antibiotics has enhanced production via effectively controlling infectious disease and promoting the growth of the chickens, allowing the industry to cope with the increased consumer demands and provide safe and affordable products [13]. But the non-judicious use of antibiotics has been attributed to food-borne outbreaks like salmonellosis, where the etiological agents have been identified as resistant clones [14]. The emergence and proliferation of resistant pathogens and the cognate decrease in the efficacy of antibiotic therapy pose a concrete risk to public health and sustainable farming [13]. The spread of such resistant strains among food animals is life-threatening as they are often non-treatable with currently available antimicrobials [15]. So, animal agriculture such as poultry farming and antibiotic usage on the farms are hot debate topics, because overuse may be a contributing factor for the entrance of AMR pathogens and AMR genes into the food chain [15]. The AMR obtained therefrom is acquired through several mechanistic and epidemiological events, including random mutation, plasmid exchange, horizontal gene transfer, and clonal spread of the resistant isolates [16]. Humans can get exposed to antibiotic-resistant bacteria through the consumption of contaminated meat and eggs or direct transmission from colonized animals or manure and litter [11]. Thereby increasing the proportion of single and multiple antibiotic-resistant isolates showing antimicrobials' resistance by pathogenic bacteria is a universal public health concern throughout the world especially in developing countries [17]. Because of the phenomenon of developing multidrug-resistant Salmonella isolates, the management of Salmonella infection using regular drugs is very difficult [11] Considering the urgency of the above, the survey of Salmonella in food animal production together with surveillance on antimicrobial resistance patterns is very essential [12]. In recent years, the development of MDR among foodborne pathogens, such as Salmonella spp., has been associated with an increase in human mortality, and longtime hospitalization due to therapy failure [11]. So, this study reports the presence of Salmonella including drug resistance pattern against commonly used antibiotics in poultry chicken in Hathazari region of Chattogram, Bangladesh.

\section{Materials and Methods}

\subsection{Study Area and Collection of Samples}

The samples were collected randomly from farms and local markets situated in Hathazari, Chattogram district of Bangladesh. This study was carried out throughout May 2019-March 2020, at the bacteriological laboratory in the Department of Microbiology, University of Chittagong. A total of 25 poultry samples, mainly 4 types as cloacal sample $(n=5)$, egg $(n=4)$, raw chicken meat $(n=$ $8)$, and raw chicken liver $(n=8)$ were collected. All samples were aseptically transported to the laboratory, labeled, maintained at $4^{\circ} \mathrm{C}$ and were analyzed as 
soon as possible. Meat and liver samples were homogenized using blender. For cloacal/fecal samples, pre-moistening $(0.1 \%$ buffered peptone water, Oxoid Ltd. England) sterile cotton tipped swab were used. The wooden shaft was broken off; and the cotton swab was left inside the conical flask [18]. Ethical approval was not required as samples were collected from local market.

\subsection{Enrichment, Isolation and Identification}

Isolation procedures were carried out according to the WHO enrichment method. Isolation of Salmonella spp. was done by pre-enrichment, selective enrichment, and selective plating techniques. Buffered peptone water, Rappaport Vassiliadis (RV), and Xylose-Lysine Deoxecholate agar media were used for pre-enrichment and selective enrichment respectively. For pre-enrichment aseptically, $25 \mathrm{gm}$ of raw chicken samples (meat, liver, egg) were mixed with $225 \mathrm{ml}$ sterile buffered peptone water (BPW). Each egg was dipped in a beaker containing sterile $225 \mathrm{ml}$ sterile buffered peptone water (BPW). The wooden shaft was broken off; and the cotton swab was left inside the conical flask containing buffered peptone water. All were incubated at $37^{\circ} \mathrm{C}$ for 24 hours. For enrichment. $0.1 \mathrm{ml}$ of the pre-enrichment culture was inoculated into the selective enrichment broth of Rappaport Vassiliadis (RV, HiMedia, Mumbai, India)) and incubated at $42^{\circ} \mathrm{C}$ for 24 hours. A loopful from each of the selective enrichment broth was streaked onto Xylose Lysine Deoxycholate agar (XLD agar, HiMedia), Salmonella-Shigella agar (SS, HiMedia), Brilliant Green Agar (BGA, HiMedia) and incubated at $37^{\circ} \mathrm{C}$ for 24 hours. The plates were examined for the presence of typical colonies of Salmonella. Salmonella isolates were stored on nutrient agar slants and kept at $4^{\circ} \mathrm{C}$. All suspected Salmonella colonies were picked from the agar plates and inoculated into the following biochemical test tubes for confirmation: triple sugar iron (TSI) test (presumptive Salmonella colonies produce black colonies or colonies with black centers and red medium on TSI agar) (OXOID, England), citrate test (presumptive Salmonella colonies produce blue color for the citrate test), urease test (presumptive Salmonella colonies produce purple-red color for the urease test), lysine decarboxylase (LDC) agar (OXOID, England) test (presumptive Salmonella colonies produce purple-colored colonies on LDC agar), and indole test (presumptive Salmonella colonies produce violet-colored colonies for the indole test). Plates were incubated for 24 or $48 \mathrm{hrs}$. at $37^{\circ} \mathrm{C}$. Colonies were also tested for catalase production.

\subsection{Species Specific PCR Amplification}

The PCR assays were performed to identify Salmonella spp. The nucleotide sequence for the Salmonella common primer used for the study was: Primer 27F: AGA GTT TGA TCM TGG CTC AG and Primer 1492 R: CGG TTA CCT TGT TAC GAC TT (18). The reaction mixture (20 ul) contained Master Mix (10 ul), T DNA (Concentration 25 - 65 ng/ul) (1 ul), Primer F (Concentration 10 - $20 \mathrm{pMol}$ ) (1 ul), Primer R (Concentration $10-20 \mathrm{pMol})(1 \mathrm{ul})$ and $7 \mathrm{ul}$ of PCR water. The PCR amplification was done by initial denaturation at $95^{\circ} \mathrm{C}$ for 3 
minutes followed by 35 cycles of denaturation at $95^{\circ} \mathrm{C}$ for 30 seconds, annealing at $48^{\circ} \mathrm{C}$ for 30 seconds and extension at $72^{\circ} \mathrm{C}$ for 90 seconds. The final extension was at $72^{\circ} \mathrm{C}$ for 5 minutes. PCR amplified products were subjected to gel $(1.5 \%$ agarose, Promega, USA) electrophoresis with ethidium bromide fluorescence (100 v for 40 minutes) and visualized in Alpha imager HP gel documentation system.

\subsection{Antimicrobial Susceptibility Test}

The antimicrobial susceptibility was performed using the disc diffusion method on Mueller-Hinton agar (HI Media, India) as described in Clinical and Laboratory Standards Institute guideline (19). Salmonella isolates were tested for susceptibility to the following 10 antibiotics (Hi Media): Neomycin $(30 \mu \mathrm{g})$, Vancomycin $(30 \mu \mathrm{g})$, Ampicillin $(25 \mu \mathrm{g})$, Amoxicillin $(30 \mu \mathrm{g})$, Chloramphenicol $(30 \mu \mathrm{g})$, Cephalexin $(30 \mu \mathrm{g})$, Doxycycline $(30 \mu \mathrm{g})$, Ciprofloxacin $(5 \mu \mathrm{g})$, Ceftazidime $(5 \mu \mathrm{g})$, Nalidixic acid $(30 \mu \mathrm{g})$ were used by the Clinical Laboratory Standards Institute (CLSI). The diameters of the zones of inhibition were recorded to the nearest $\mathrm{mm}$ and classified as resistant, intermediate, or susceptible according to the established interpretive chart.

\subsection{Statistical Analysis}

The data were entered in spreadsheets, later the data were imported for analysis into IBM SPSS Statistics version 22 software (SPSS inc., Chicago, IL, USA).

\section{Result}

\subsection{Prevalence of Salmonella spp.}

A total of 25 samples, 12 samples were positive for Salmonella spp. based on cultural and biochemical properties followed by citrate, catalase, and MR tests, Urease, Oxidase, VP, and Indole tests. Salmonella spp. produced characteristics pinkish-white colonies on BGA media, black centered red colonies on XLD media, and black centered colorless colonies on SS agar with an overall prevalence of $48 \%$. In the distribution of Salmonella spp. among different samples, a higher isolation rate was noticed in 5 out of 8 raw meat samples (62.5\%), while the lowest detection rate was 3 out of 8 raw liver samples (37.5\%) was observed (Table $1)$.

Table 1. Presence of positive Salmonella spp. in poultry sample.

\begin{tabular}{cccc}
\hline $\begin{array}{c}\text { Sample } \\
\text { Source }\end{array}$ & $\begin{array}{c}\text { No. of } \\
\text { Sample tested }\end{array}$ & $\begin{array}{c}\text { No. of Salmonella spp. } \\
\text { Positive sample }\end{array}$ & $\begin{array}{c}\text { Presence of Salmonella } \\
\text { positive Sample }\end{array}$ \\
\hline Raw Chicken meat & 8 & 5 & $62.5 \%$ \\
Raw Chicken liver & 8 & 3 & $37.5 \%$ \\
Cloacal Swab & 5 & 2 & $40 \%$ \\
Egg shell & 4 & 2 & $50 \%$ \\
\hline
\end{tabular}




\subsection{Antibiotic Resistance Pattern of Salmonella spp.}

To determine the antibiotic sensitivity patterns of the isolates, the agar diffusion method was used. Ten commonly used antibiotics of different antibiotic groups were used to examine the antibiotic susceptibility of all the 12 Salmonella isolates. The antibiotics were selected based on CLSI 2020 guidelines, and current practice [19]. Variable rates of resistance of Salmonella spp. were observed from the total of 12 isolates against a panel of 10 selected antibiotics, including the commonly used antibiotics for salmonellosis treatment shown in Table 2. From Table 2, it has been observed that all isolates (From ES-1 to ES-12) are resistant against at least one antibiotic. Among them ES-2 and ES-3 exhibited multidrug resistance against 7 antibiotics as well as intermediate resistance against Amoxicillin, Ceftazidime and Ciprofloxacin respectively.

The antimicrobial resistance testing revealed that all the isolates $(n=12)$ exhibited $100 \%$ resistance to vancomycin and cephalexin, followed by ampicillin (75\%), nalidixic acid (58.33\%), chloramphenicol (41.66\%), doxycycline (50\%), and neomycin (50\%) (Figure 1). Interestingly, none of the isolates were shown to be resistant to amoxicillin, ciprofloxacin, and ceftazidime. According to Table 3 , the highest resistance was recorded for vancomycin and cephalexin (100\%) and the lowest resistance was for chloramphenicol (41.66\%).

Table 2. Antimicrobial susceptibility pattern of isolated Salmonella spp.

\begin{tabular}{ccccccccccc}
\hline \multirow{2}{*}{ Isolates } & \multicolumn{7}{c}{ Antibiotics Name } \\
\cline { 2 - 10 } & AMP & C & NA & AMX & CN & CAZ & N & CIP & DO & VA \\
\hline ES-1 & I & R & R & S & R & S & I & S & R & R \\
ES-2 & R & R & R & S & R & S & R & I & R & R \\
ES-3 & R & R & R & I & R & I & R & I & R & R \\
ES-4 & I & I & R & S & R & S & S & S & I & R \\
ES-5 & R & S & R & S & R & S & R & S & R & R \\
ES-6 & R & R & I & S & R & S & I & S & S & R \\
ES-7 & R & R & R & I & R & S & R & S & R & R \\
ES-8 & R & S & R & S & R & S & I & S & S & R \\
ES-9 & S & S & S & S & R & S & I & S & I & R \\
ES-10 & R & S & S & S & R & S & R & S & I & R \\
ES-11 & R & S & S & S & R & S & R & S & I & R \\
ES-12 & R & I & I & S & R & S & S & S & R & R \\
\hline
\end{tabular}

Note: AMP = Ampicillin, $\mathrm{C}=$ Chloramphenicol; $\mathrm{NA}=$ Nalidixic acid; AMX = Amoxicillin $\mathrm{CN}=$ Cephalexin, $\mathrm{CAZ}=$ Ceftazidime; $\mathrm{N}=$ Neomycin, $\mathrm{CIP}=$ Ciprofloxacin, $\mathrm{DO}=$ Doxycycline, $\mathrm{VA}=$ Vancomycin, $\mathrm{S}=$ Sensitive, $\mathrm{I}=$ Intermediate resistant, $\mathrm{R}=$ Resistant. 
Table 3. Percentage of resistant, intermediate and sensitive strains against individual antibiotic.

\begin{tabular}{cccccc}
\hline Generation of Antibiotic & Group of Antibiotic & Name of Antibiotic & Resistant (\%) & Intermediate (\%) & Sensitive (\%) \\
\hline \multirow{2}{*}{$1^{\text {st }}$} & \multirow{2}{*}{ Aminoglycosides } & Neomycin & $6(50 \%)$ & $4(33.33 \%)$ & $2(16.67 \%)$ \\
& & Vancomycin & $12(100 \%)$ & $0(0 \%)$ & $0(0 \%)$ \\
\hline \multirow{2}{*}{$2^{\text {nd }}$} & Penicillin & Ampicillin & $9(75 \%)$ & $2(16.67 \%)$ & $1(8.33 \%)$ \\
& \multirow{2}{*}{ Beta lactams } & Amoxicillin & $0(0 \%)$ & $1(8.33 \%)$ & $11(91.67 \%)$ \\
& Cephalosporin & Chloramphenicol & $5(41.66 \%)$ & $2(16.67 \%)$ & $1(8.33 \%)$ \\
& Tetracycline & Doxycycline & $6(50 \%)$ & $4(33.33 \%)$ & $2(16.67 \%)$ \\
\hline \multirow{2}{*}{$3^{\text {rd }}$} & Quinolones & Nalidixic acid & $7(58.33 \%)$ & $2(16.67 \%)$ & $3(25 \%)$ \\
& Cephalosporin & Ciprofloxacin & $0(0 \%)$ & $2(16.67 \%)$ & $10(83.33 \%)$ \\
& & Ceftazidime & $0(0 \%)$ & $1(8.33 \%)$ & $11(91.67 \%)$ \\
\hline
\end{tabular}

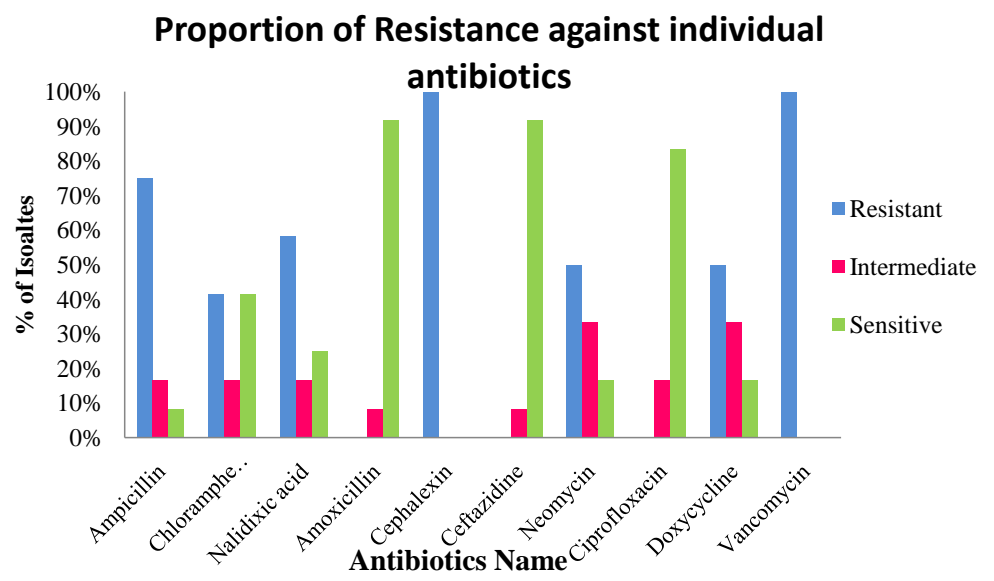

Figure 1. Antibiotic resistance ratio of Salmonella spp. against 10 antibiotics.

\subsection{Multi-Drug Resistance}

In our study, the multidrug resistance feature of the isolates has been also evaluated (Table 4). According to the study, 11 isolates (91.66\%) out of 12 strains were multidrug-resistant to $\geq 3$ antimicrobials and 6 multidrug resistance profiles were observed. All the isolates $(n=12)$ were resistant to at least one antibiotic. 2 isolates (16.67\%) were showing resistance for three antibiotics, 4 isolates (33.33\%) were showing resistance for four antibiotics, and 1 isolate $(8.33 \%)$ was showing resistance for five antibiotics and 4 isolates (33.33\%) were showing resistance for seven antibiotics. The number of isolates resistant to seven drugs was higher followed by four-drug resistant isolates. So, AMP-C-NA-N-CN-DO-VA $(4 / 12)$ was the most frequently occurred phenotype in this study.

\subsection{Molecular Identification of Salmonella spp.}

Among the 12 isolates, two multidrug-resistant strains of Salmonella as $\mathrm{ES}_{2}$ and $\mathrm{ES}_{3}$ were identified and classified based on their 16S rRNA gene sequences using Primer 27F: AGA GTT TGA TCM TGG CTC AG and Primer 1492 R: CGG TTA CCT TGT TAC GAC TT (18). Two directional sequences were done using forward and reverse primers to obtain full-length sequences (1465 bp) 
(Figure 2). The sequence similarities were then examined NCBI -BLAST. The isolate $\mathrm{ES}_{2}$ was found to have the highest probability of $99.56 \%$ with Salmonella enterica subsp. enterica strain Ty2 $16 \mathrm{~S}$ ribosomal RNA, partial sequence, and the isolate $\mathrm{ES}_{3}$ was found to have the highest probability $98.26 \%$ with Salmonella enterica subsp. enterica serovar Typhimurium strain ATCC 13311. Both strains have been approved as novel strain Salmonella enterica strain Eshaa2 (Figure 3), Accession no. MT163513 and Salmonella enterica strain Eshiika3 (Figure 4), Accession no. MT164531 respectively using Genbank database of the National Center for Biotechnology Information (NCBI, http://www.ncbi.nih.gov).

Table 4. Multidrug resistance pattern of Salmonella spp.

\begin{tabular}{ccccc}
\hline $\begin{array}{c}\text { Number of } \\
\text { antimicrobials }\end{array}$ & Resistance pattern & $\begin{array}{c}\text { No. of } \\
\text { isolates }\end{array}$ & $\begin{array}{c}\text { Percentages } \\
\text { of isolates (\%) }\end{array}$ & $\begin{array}{c}\text { MDR } \\
(\%)\end{array}$ \\
\hline \multirow{2}{*}{ Three } & NA-CN-VA & 1 & $2(16.66 \%)$ & \\
& AMP-CN-VA & 1 & & \\
\multirow{2}{*}{ Four } & AMP-NA-CN-VA & 1 & $4(33.33 \%)$ & $11(91.66 \%)$ \\
\multirow{2}{*}{ Five } & AMP-N-CN-VA & 3 & $1(8.33 \%)$ & \\
Seven & C-NA-CN-DO-VA & 1 & $1(33.33 \%)$ & \\
\hline
\end{tabular}

Note: $\mathrm{AMP}=$ Ampicillin, $\mathrm{C}=$ Chloramphenicol; $\mathrm{NA}=$ Nalidixic acid; $\mathrm{AMX}=$ Amoxicillin $\mathrm{CN}=$ Cephalexin, $\mathrm{CAZ}=$ Ceftazidime; $\mathrm{N}=$ Neomycin, $\mathrm{CIP}=$ Ciprofloxacin, $\mathrm{DO}=$ Doxycycline, $\mathrm{VA}=$ Vancomycin.

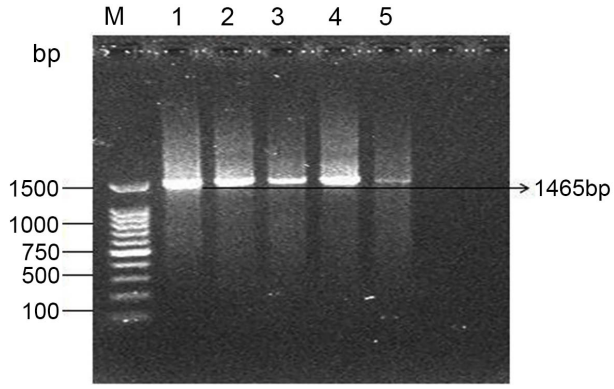

Figure 2. Agarose gel electrophoresis (1.5\%) of PCR products after amplification of $16 \mathrm{~S}$ rRNA for Salmonella spp. Lane M-1 Kbp DNA ladder, Lane 1 - 5: Extracted DNA sample.

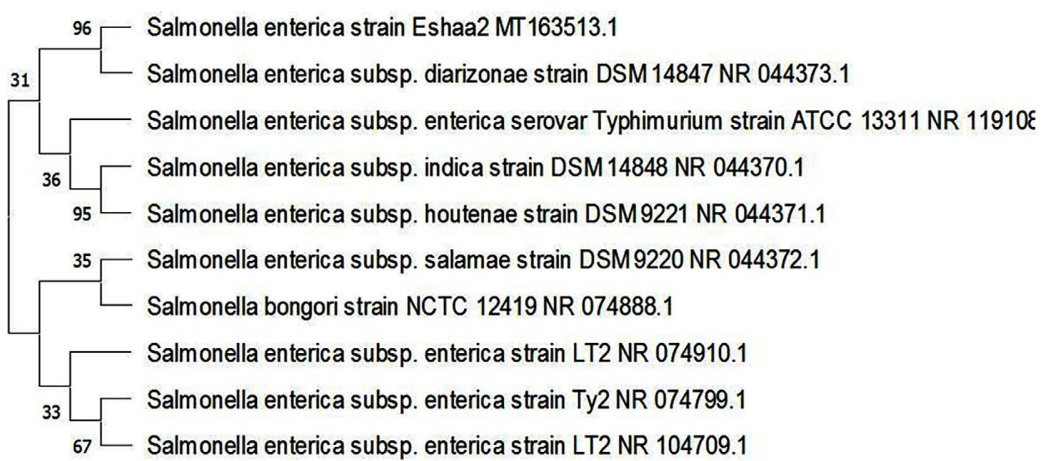

Figure 3. Phylogenetic tree of ES-2 derived from maximum likelihood analysis of the $16 \mathrm{~S}$ rRNA genes of 10 species from Enterobacteriaceae family. 


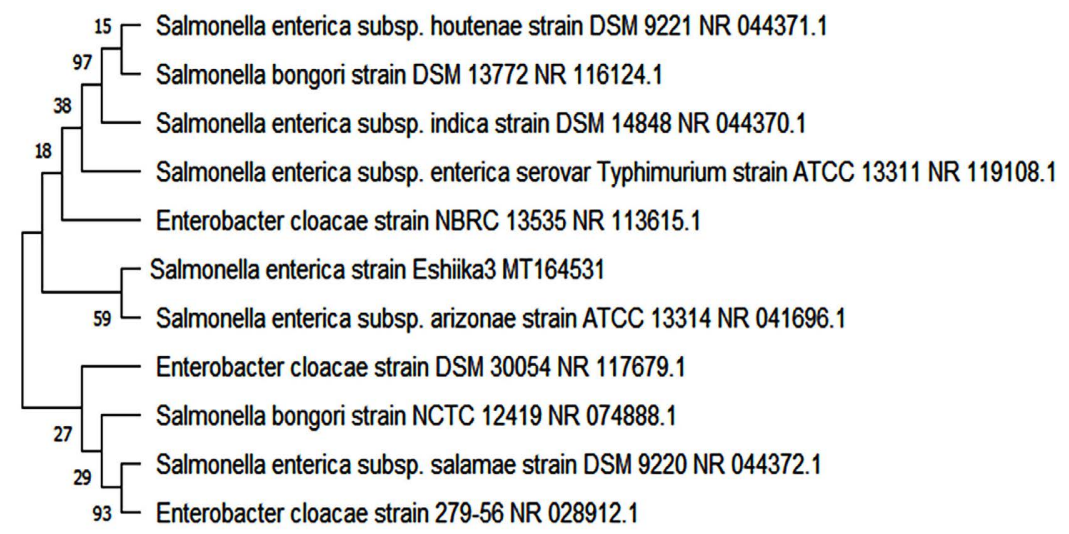

Figure 4. Phylogenetic tree of ES-3 derived from maximum likelihood analysis of the $16 \mathrm{~S}$ rRNA genes of 10 species from Enterobacteriaceae family.

\section{Discussion}

Non-typhoidal Salmonella is considered to be the leading cause of food-borne illness which poses a great problem for the poultry industry and human health in both developing and non-developing countries [20]. Salmonellosis remains one of the most frequent food-borne zoonosis constituting a worldwide major public health concern [6]. Currently, at a global level, the main source of infection for humans includes poultry products (meat, liver, eggs) [7].

We found a considerable high frequency (48\%) of contamination in poultry samples with Salmonella spp. (Table 1) which is higher than the recent study in the same area where the prevalence is $29 \%$ [16]. The occurrence of Salmonella contamination has also been reported from various parts of the world ranging from $17 \%-53 \%$ [21] [22] [23] [24]. The prevalence difference could be due to differences in experimental location, environmental condition, sample type, hygiene practice, overall management, and surveillance systems. Among the different poultry samples, distribution of Salmonella in Cloacal swab (40\%), raw meat $62.5 \%$, raw liver $37.5 \%$, and eggshell $50 \%$ are observed. The prevalence of Salmonella contamination of raw meat (62.5\%) observed in this study is significantly high which is in agreement with results reported in Belgium, The United Kingdom, Iran, China, Iraq, and the Russian Federation [25]. This significant variation in the prevalence could be due to sampling procedure, sanitation within the slaughterhouse, possible contamination during poultry processing steps (e.g. the amount of cross-contamination of chicken carcasses by contact with intestinal tracts during slaughter or processing). In our result prevalence of Salmonella on eggshells, the surface is significantly higher (50\%). The prevalence of Salmonella was reported at $40 \%$ in eggshells in a previous study carried out in Pakistan and $6.1 \%$ in India [26]. One possible cause of Salmonella contamination in developing countries is repeated use of the same egg-storing trays. Egg-storing trays contamination might be due to chicken fecal material or due to environmental factors [26]. So, possible horizontal transmission of Salmonella into an egg which is likely to be cross-contamination from feces or the cage environment could be happened [27]. 
Resistance of Salmonella to antimicrobials is an emerging problem in developing and developed countries [28]. The result from the present study demonstrated a high level of resistance to vancomycin (100\%), cephalexin (100\%) followed by ampicillin (75\%), nalidixic acid (58\%), chloramphenicol (41\%), Doxycycline (50\%) and neomycin (50\%) shown in Table 3. Ampicillin, doxycycline, nalidixic acid, and several other antibiotics are widely used as animal feed additives due to their low cost and availability [29]. Indeed, increased use of antibiotics in poultry industries for therapeutic, prophylactic, and growth-promoting purposes increases the selective pressure for resistant phenotypes for applied antibiotics [30]. Chloramphenicol is used to treat human salmonellosis, due to its low cost and adequate therapeutic response [31]. Another most widely used drug for salmonellosis treatment is doxycycline belonging to the group tetracycline. In the present study, $41 \%$ for chloramphenicol and $50 \%$ isolates were resistant to considerably high doxycycline, due to its unwise and continuous utilization in poultry farms. It has increased microbial resistance, consequently reducing the available therapeutic options. The resistance of bacteria to such drugs has increased and represented a substantial cost to public health [32].

Salmonella serotypes with multidrug-resistant phenotypes are a threat to the poultry of Bangladesh [33]. A considerably high proportion of isolates (11/12, 91.67\%) (Table 4) was resistant to three or more antibiotics and 11 multidrug profiles were observed (Table 4). According to the study, two isolates (16.67\%) were resistant to 3 drugs, four isolates (33.37\%) to 4 drugs, 1 isolate (8.33\%) were resistant to 5 drugs and 4 isolates (33.37\%) were resistant to 7 drugs. The AMP-C-NA-N-CN-DO-VA (4/12) was the most frequently occurred phenotype. These types of antibiotic-resistant for the isolates in this study are also in agreement with different reports in other parts of African and European countries [34]. Ongoing infection with Salmonella organism and use of medication at breeder level could significantly amplify the prevalence of multiple resistant Salmonella in poultry rearing environment in Bangladesh [35]. Transfer of resistance plasmid to other bacteria facilitates multi-drug resistance. This puts the public health at risk for future antibiotic resistant infection.

In this regard, our antibiogram study suggests that chicken could be a source of multidrug-resistant salmonellosis in human. Similar findings on multidrug resistance among Salmonella strains have been reported from Bangladesh and various parts of the world [36]. On the other hand, the third generation fluoroquinolone-class antibiotic ciprofloxacin showed $83.33 \%$ sensitivity, a similar finding was reported by Bangladesh [28]. Cephalosporin group ceftazidime and penicillin group amoxicillin, both antibiotics showed $91.6 \%$ susceptibility which was in agreement with several studies where the least resistance was found [28] [37]. This could be an important indication for a mass community for choosing the effective antibiotics to treat diseases caused by Salmonella spp.

In the current study, elevated levels of prevalence and increased amount of antibiotic resistance in Salmonella have been detected in broiler chicken. Though the study was on pilot scale, these findings recommended that, in Ban- 
gladesh, poultry is a major avenue of multidrug-resistant Salmonella and suggest that it is difficult to achieve successful antimicrobial therapy for human salmonellosis caused by the strain of poultry origin.

\section{Limitations}

Due to fund constraints and COVID-19 pandemic issues, less sample size was taken to conduct this study.

\section{Conclusion}

In the present study, the high prevalence and the detection of multidrug resistant strain highlight the poor management system in the poultry farm. Poultry has been reported as a source of nontyphoidal Salmonella which are resistant to clinically relevant antibiotics and remarkably pose a high risk to both animals and humans. Moreover, indiscriminate use of antimicrobials in poultry animals for growth promotion and disease prevention is considered the key driver behind the surge. More attention should be focused on increasing antibiotic surveillance capacity to cope with the spread of emerging resistance and on the alternative therapeutic approaches.

\section{Recommendations}

For validating more reliability, this research needs further work with greater sample size.

\section{Acknowledgements}

The authors would like to thank Professor Dr. Seraj Uddin, Department of Microbiology, University of Ghittagong, for his valuable suggestions and advices also thank Dr. Zobaidul Alam, Department of Microbiology, University of Chittagong for providing laboratory facilities.

\section{Authors' Contribution}

Supervised and designed the experiment: KNI, MMH;

Performed the lab work: EE, TC;

Wrote the manuscript: EE, KNI;

Data analysis: EE, KNI and SZ. Improved the manuscript: SZ and KNI;

All authors read and approved the final manuscript.

\section{Conflicts of Interest}

The authors declare no conflicts of interest regarding the publication of this paper.

\section{References}

[1] Asfaw, G., Ali, D., Tadesse, B. and Ebabu, A. (2020) Prevalence and Antibiotic Resistance Pattern of Salmonella Isolated from Caecal Contents of Exotic Chicken in 
Debre Zeit and Modjo, Ethiopia. International Journal of Microbiology, 2020, Article ID: 1910630.

[2] Carrasco, E., Morales-Rueda, A. and García-Gimeno, R.M. (2012) Cross-Contamination and Recontamination by Salmonella in Foods: A Review. Food Research International, 45, 545-556. https://doi.org/10.1016/j.foodres.2011.11.004

[3] Foley, S.L., Nayak, R., Hanning, I.B., Johnson, T.J., Han, J. and Ricke, S.C. (2011) Population Dynamics of Salmonella enterica Serotypes in Commercial Egg and Poultry Production. Applied and Environmental Microbiology, 77, 4273-4279.

[4] Barua, H., Biswas, P.K., Talukder, K.A., Olsen, K.E. and Christensen, J.P. (2014) Poultry as a Possible Source of Non-Typhoidal Salmonella enterica Serovars in Humans in Bangladesh. Veterinary Microbiology, 168, 372-380. https://doi.org/10.1016/j.vetmic.2013.11.020

[5] Karim, M.R., Giasuddin, M., Samad, M.A., Mahmud, M.S., Islam, M.R., Rahman, M.H. and Yousuf, M.A. (2017) Prevalence of Salmonella spp. in Poultry and Poultry Products in Dhaka, Bangladesh. International Journal of Animal Biology, 3, 18-22.

[6] Manoj, J., Singh, M.K. and Singh, Y.P. (2015) The Role of Poultry in Food Borne Salmonellosis and Its Public Health Importance. Advances in Animal and Veterinary Sciences, 3, 485-490. https://doi.org/10.14737/journal.aavs/2015/3.9.485.490

[7] Nair, D.V.T. and Johny, A.K. (2019) Salmonella in Poultry Meat Production. In: Venkitanarayanan, K., Thakur, S. and Ricke S., Eds., Food Safety in Poultry Meat Production, Springer, Cham, 1-24. https://doi.org/10.1007/978-3-030-05011-5 1

[8] Rahman, M.S., Jang, D.H. and Yu, C.J. (2017) Poultry Industry of Bangladesh: Entering a New Phase. Korean Journal of Agricultural Science, 44, 272-282. https://doi.org/10.7744/kjoas.20170027

[9] Khatun, R., Howlader, A.J., Ahmed, S., Hasan, A., Islam, N., Haider, S. and Mahmud, M.S. (2018) Quality Assessment of Poultry Farm and Product Processing Unit in Different Divisions of Bangladesh. Public Health and Preventive Medicine, 4, $1-10$.

[10] Hoque, N., Mohiuddin, R.B., Khan, M.M.H., Hannan, M. and Alam, J. (2019) Outbreak of Salmonella in Poultry of Bangladesh and Possible Remedy. Journal of Advanced Biotechnology and Experimental Therapeutics, 2, 87-97. https://doi.org/10.5455/jabet.2019.d30

[11] Alam, S.B., Mahmud, M., Akter, R., Hasan, M., Sobur, A., Nazir, K.H.M., Noreddin, A., Rahman, T., El Zowalaty, M.E. and Rahman, M. (2020) Molecular Detection of Multidrug Resistant Salmonella Species Isolated from Broiler Farm in Bangladesh. Pathogens, 9, Article No. 201. https://doi.org/10.3390/pathogens9030201

[12] Samad, M.A. (2011) Public Health Threat Caused by Zoonotic Diseases in Bangladesh. Bangladesh Journal of Veterinary Medicine, 9, 95-120.

[13] Kassem, I.I., Helmy, Y.A., Kashoma, I.P. and Rajashekara, G. (2016) The Emergence of Antibiotic Resistance on Poultry Farms. Achieving Sustainable Production of Poultry Meat: Safety, Quality and Sustainability, 1, 67-80. https://doi.org/10.19103/AS.2016.0010.05

[14] Nair, D.V.T., Venkitanarayanan, K. and Johny, A.K. (2018) Antibiotic-Resistant Salmonella in the Food Supply and the Potential Role of Antibiotic Alternatives for Control. Foods, 7, Article No. 167. https://doi.org/10.3390/foods7100167

[15] Davis, M.F., Price, L.B., Liu, C.M.H. and Silbergeld, E.K. (2011) An Ecological Perspective on US Industrial Poultry Production: The Role of Anthropogenic Ecosystems on the Emergence of Drug-Resistant Bacteria from Agricultural Environments. Current Opinion in Microbiology, 14, 244-250. 
https://doi.org/10.1016/j.mib.2011.04.003

[16] Ali, F., Silvy, T.N., Hossain, T.J., Uddin, M.K. and Uddin, M.S. (2021) Prevalence and Antimicrobial Resistance Phenotypes of Salmonella Species Recovered at Various Stages of Broiler Operations in Hathazari, Bangladesh. International Journal of One Health, 7, 158-164. https://doi.org/10.14202/IJOH.2021.158-164

[17] Fair, R.J. and Tor, Y. (2014) Antibiotics and Bacterial Resistance in the 21st Century. Perspectives in Medicinal Chemistry, 6, PMC-S14459. https://doi.org/10.4137/PMC.S14459

[18] International Organization for Standardization (ISO) (2004) Microbiology of Food and Animal Feeding Stuffs. Horizontal Method for the Detection of Salmonella spp.

[19] Weinstein, M.P. and Lewis, J.S. (2020) The Clinical and Laboratory Standards Institute Subcommittee on Antimicrobial Susceptibility Testing: Background, Organization, Functions, and Processes. Journal of Clinical Microbiology, 58, e 01864-19.

[20] Stevens, A., Kaboré, Y., Perrier-Gros-Claude, J.D., Millemann, Y., Brisabois, A., Catteau, M., Cavin, J.F. and Dufour, B. (2006) Prevalence and Antibiotic-Resistance of Salmonella Isolated from Beef Sampled from the Slaughterhouse and from Retailers in Dakar (Senegal). International Journal of Food Microbiology, 110, 178-186. https://doi.org/10.1016/j.ijfoodmicro.2006.04.018

[21] Logue, C.M., Sherwood, J.S., Olah, P.A., Elijah, L.M. and Dockter, M.R. (2003) The Incidence of Antimicrobial-Resistant Salmonella spp. on Freshly Processed Poultry from US Midwestern Processing Plants. Journal of Applied Microbiology, 94, 16-24. https://doi.org/10.1046/j.1365-2672.2003.01815.x

[22] Domınguez, C., Gomez, I. and Zumalacarregui, J. (2002) Prevalence of Salmonella and Campylobacter in Retail Chicken Meat in Spain. International Journal of Food Microbiology, 72, 165-168. https://doi.org/10.1016/S0168-1605(01)00638-9

[23] Chung, Y.H., Kim, S.Y. and Chang, Y.H. (2003) Prevalence and Antibiotic Susceptibility of Salmonella Isolated from Foods in Korea from 1993 to 2001. Journal of Food Protection, 66, 1154-1157. https://doi.org/10.4315/0362-028X-66.7.1154

[24] Ribeiro, A.R., Kellermann, A., Santos, L.R.D., Bessa, M.C. and Nascimento, V.P.D. (2007) Salmonella spp. in Raw Broiler Parts: Occurrence, Antimicrobial Resistance Profile and Phage Typing of the Salmonella enteritidis Isolates. Brazilian Journal of Microbiology, 38, 296-299. https://doi.org/10.1590/S1517-83822007000200021

[25] Mahdavi, S., Azizi Dehbokri, M. and Isazadeh, A. (2018) Contamination of Chicken Meat with Salmonella spp. Distributed in Mahabad City, Iran. International Journal of Enteric Pathogens, 6, 65-68. https://doi.org/10.15171/ijep.2018.18

[26] Suresh, T., Hatha, A.A.M., Sreenivasan, D., Sangeetha, N. and Lashmanaperumalsamy, P. (2006) Prevalence and Antimicrobial Resistance of Salmonella enteritidis and Other Salmonellas in the Eggs and Egg-Storing Trays from Retails Markets of Coimbatore, South India. Food Microbiology, 23, 294-299. https://doi.org/10.1016/j.fm.2005.04.001

[27] Utrarachkij, F., Pornraungwong, S., Siripanichgon, K., Nakajima, C., Suzuki, Y. and Suthienkul, O. (2012) Possible Horizontal Transmission of Salmonella via Reusable Egg Trays in Thailand. International Journal of Food Microbiology, 154, 73-78. https://doi.org/10.1016/j.ijfoodmicro.2011.12.024

[28] Asif, M., Rahman, H., Qasim, M., Khan, T.A., Ullah, W. and Jie, Y. (2017) Molecular Detection and Antimicrobial Resistance Profile of Zoonotic Salmonella enteritidis Isolated from Broiler Chickens in Kohat, Pakistan. Journal of the Chinese Medical Association, 80, 303-306. https://doi.org/10.1016/j.jcma.2016.11.007

[29] Acharya, K.P. and Wilson, R.T. (2019) Antimicrobial Resistance in Nepal. Frontiers 
in Medicine, 6, Article No. 105. https://doi.org/10.3389/fmed.2019.00105

[30] Mehdi, Y., Létourneau-Montminy, M.P., Gaucher, M.L., Chorfi, Y., Suresh, G., Rouissi, T., Brar, S.K., Côté, C., Ramirez, A.A. and Godbout, S. (2018) Use of Antibiotics in Broiler Production: Global Impacts and Alternatives. Animal Nutrition, 4, 170-178. https://doi.org/10.1016/j.aninu.2018.03.002

[31] Alecrim, W.D., Loureiro, A.C.D.S.P., Moraes, R.S., Monte, R.L. and Lacerda, M.V.G.D. (2002) Febre tifóide: Recaída por resistência antimicrobiana. Relato de caso. Revista da Sociedade Brasileira de Medicina Tropical, 35, 661-663. https://doi.org/10.1590/S0037-86822002000600019

[32] Li, B.Y. and Webster, T.J. (2018) Bacteria Antibiotic Resistance: New Challenges and Opportunities for Implant-Associated Orthopedic Infections. Journal of Orthopaedic Research, 36, 22-32. https://doi.org/10.1002/jor.23656

[33] Sultana, M., Bilkis, R., Diba, F. and Hossain, M.A. (2014) Predominance of Multidrug Resistant Zoonotic Salmonella enteritidis Genotypes in Poultry of Bangladesh. The Journal of Poultry Science, 51, 424-434. https://doi.org/10.2141/jpsa.0130222

[34] Thorns, C.J. (2000) Bacterial Food-Borne Zoonoses. Revue Scientifique et Technique (International Office of Epizootics), 19, 226-239. https://doi.org/10.20506/rst.19.1.1219

[35] Mahmud, T., Hassan, M.M., Alam, M., Khan, M.M., Bari, M.S. and Islam, A. (2013) Prevalence and Multidrug-Resistant Pattern of Salmonella from the Eggs and Egg-Storing Trays of Retail Markets of Bangladesh. International Journal of One Health, 2, 7-11.

[36] Akond, M.A., Shirin, M., Alam, S., Hassan, S.M.R., Rahman, M.M. and Hoq, M. (2012) Frequency of Drug Resistant Salmonella spp. Isolated from Poultry Samples in Bangladesh. Stamford Journal of Microbiology, 2, 15-19.

[37] Rahman, M.A., Rahman, A.K.M.A., Islam, M.A. and Alam, M.M. (2018) Detection of Multi-Drug Resistant Salmonella from Milk and Meat in Bangladesh. Bangladesh Journal of Veterinary Medicine, 16, 115-120. 